\title{
SAGES' guidelines for diagnosis, treatment, and use of laparoscopy for surgical problems during pregnancy
}

\author{
Nathaniel J. Soper
}

Published online: 22 September 2011

(C) Springer Science+Business Media, LLC 2011

Since the introduction of laparoscopic cholecystectomy in the late 1980s surgeons have experienced much angst when confronted with a pregnant woman requiring operative treatment. Should surgical intervention be entertained? Is laparoscopy under these circumstances safe? If laparoscopy is contemplated, during which trimester can it be performed most safely? Should intraoperative fetal monitoring be performed? Should tocolytics be employed routinely?

In the early 1990s several studies using a pregnant ewe model demonstrated fetal acidosis accompanying a $\mathrm{CO}_{2}$ pneumoperitoneum [1], increasing surgeons' anxiety about using laparoscopy at all during pregnancy. Ultimately, most surgeons developed a conservative approach. The accepted wisdom was that surgery, including laparoscopy, was best done in the second trimester, avoiding the period of maximal organogenesis in the first trimester and the risk of premature labor in the third trimester [2]. Many patients with symptomatic cholelithiasis were urged to defer surgery until after delivery unless the "golden window" of the second trimester could be utilized, when a laparoscopic approach could be entertained.

In this issue of Surgical Endoscopy, the SAGES Guidelines Committee has debunked most of the aforementioned wives' tales. A comprehensive review of the literature was undertaken; the quality of evidence and strength of recommendations were determined using the GRADE system to encompass most of the pressing issues related to laparoscopy during pregnancy. The reader will

N. J. Soper $(\bowtie)$

Department of Surgery, Northwestern University Feinberg

School of Medicine, NMH/Galter Room 3-150, 251 E. Huron,

Chicago, IL 60611, USA

e-mail: nsoper@nmh.org notice that the quality of evidence in virtually all instances is either weak or moderate-few, if any, prospective randomized trials have been performed in this arena. Having said that, the committee members were able to assign strong recommendations to the majority of the issues. I personally have learned a great deal from reading this set of guidelines [3].

Several overarching themes become apparent. As related by the authors and stated by Sir Zachary Cope in 1921, "Earlier diagnosis means better prognosis" [4]. Generally, standard diagnostic tests can be undertaken with appropriate caution to minimize ionizing radiation to the fetus. Laparoscopic surgery, with correct patient positioning and deep vein thrombosis (DVT) prophylaxis, as well as abdominal entry and port placement modified appropriately, can be safely entertained during any trimester of pregnancy-not only during the previously privileged second trimester. That is to say, necessary surgical therapy should be rendered with the same considerations given nonpregnant individuals. In general, what's best for the mother is also best for the fetus; in most abdominal operations, the laparoscopic approach should be preferred over laparotomy. Perioperative monitoring of the mother's endtidal $\mathrm{CO}_{2}$ and the fetal heart tones should be undertaken and an obstetrical consult obtained when possible. Tocolytics should be administered only when necessary.

None of these general statements is rocket science, but many of them challenge long-held beliefs. The Guidelines Committee should be congratulated for a well-researched, complete, and authoritative re-examination of the major issues relating to surgery during pregnancy, and to laparoscopic surgery in particular. Their recommendations should affect the practice of many general surgeons and will undoubtedly change the way I approach the pregnant patient requiring a laparoscopic procedure. 


\section{References}

1. Hunter JG, Swanstrom LL, Thornburg K (1995) Carbon dioxide pneumoperitoneum induces fetal acidosis in a pregnant ewe model. Surg Endosc 9:272-277

2. Soper NJ, Hunter JG, Petrie RH (1992) Laparoscopic cholecystectomy during pregnancy. Surg Endosc 6:115-117
3. Pearl J, Price R, Richardson W (2011) SAGES' guidelines for diagnosis, treatment, and use of laparoscopy for surgical problems during pregnancy. Surg Endosc 25. doi:10.1007/s00464-0111927-3

4. Baer J (1932) Appendicitis in pregnancy with changes in position and axis of the normal appendix in pregnancy. JAMA 98: $1359-1364$ 